\title{
Simian malaria in wild macaques: first report from Hulu Selangor district, Selangor, Malaysia
}

Rumana Akter ${ }^{1}$, Indra Vythilingam² ${ }^{*}$, Loke Tim Khaw², Rajes Qvist ${ }^{1}$, Yvonne Ai-Lian Lim², Frankie Thomas Sitam³, Balan Venugopalan ${ }^{4}$ and Shamala Devi Sekaran ${ }^{5}$

\begin{abstract}
Background: Malaria is a vector-borne parasitic disease which is prevalent in many developing countries. Recently, it has been found that Plasmodium knowlesi, a simian malaria parasite can be life-threatening to humans. Long-tailed macaques, which are widely distributed in Malaysia, are the natural hosts for simian malaria, including P. knowlesi. The aim of the present study was to determine the prevalence of simian malaria parasites in long-tailed macaques in the district of Hulu Selangor, Selangor, Malaysia.
\end{abstract}

Methods: A total of 70 blood samples were collected from Macaca fascicularis dwelling in the forest of Hulu Selangor by the Department of Wildlife and National Parks Peninsular Malaysia, Kuala Lumpur, Malaysia. DNA was extracted using PureLink ${ }^{\mathrm{TM}}$ Genomic DNA Kits. Conventional and nested PCR were used to detect the genus and species of Plasmodium parasites respectively. In addition, phylogenetic analysis was carried out to confirm the species of Plasmodium parasites.

Results: Thirty-five (50 \%) of the 70 samples were positive for Plasmodium using genus-specific primers. These positive samples were then subjected to nested PCR targeting the $18 \mathrm{~S}$ ribosomal RNA genes to detect all five simian malaria parasites: namely, P. knowlesi, Plasmodium inui, Plasmodium cynomolgi, Plasmodium fieldi, and Plasmodium coatneyi. All five species of simian malaria parasites were detected. Of these, P. inui was the predominant (65.7 \%), followed by P. knowlesi (60 \%), P. cynomolgi (51.4\%) P. coatneyi (45.7\%) and P. fieldi (2.9\%). A total of nine macaques had monoinfection with P. knowlesi (four), P. cynomolgi (two), P. coatneyi (two) and P. fieldi (one). Eleven of the macaques had dual infections while 12 had triple infections. Three macaques were infected with four species of Plasmodium. Molecular and phylogenetic analysis confirmed the five species of Plasmodium parasites.

Conclusion: This study has provided evidence to elucidate the presence of transmission of malaria parasites among the local macaques in Hulu Selangor. Since malaria is a zoonosis, it is important to determine the new control strategies for the control of malaria.

Keywords: Simian malaria, Long-tailed macaques, Hulu Selangor

\section{Background}

Malaria remains a public health problem in many tropical and sub-tropical regions. It is caused by the blood protozoan parasites of the genus Plasmodium which has

\footnotetext{
*Correspondence: indra.vythilingam@gmail.com

${ }^{2}$ Department of Parasitology, Faculty of Medicine, University of Malaya,

50603 Kuala Lumpur, Malaysia

Full list of author information is available at the end of the article
}

been affecting humans since ancient times [1,2]. According to the World Malaria Report 2014, around 198 million people were affected by malaria in 2013 with an estimated 58.4 million deaths [3]. Traditionally, only four species of Plasmodium, namely Plasmodium falciparum, Plasmodium malariae, Plasmodium ovale, and Plasmodium vivax were known to infect humans. However in 2004, Singh et al. [4] reported a large number of malaria cases in Sarawak to be caused by Plasmodium knowlesi, 
a simian malaria parasite. This resulted in the suggestion that $P$. knowlesi could be considered the fifth species of Plasmodium known to infect humans [5].

Plasmodium knowlesi mainly circulates among longtailed (Macaca fascicularis) and pig-tailed macaques (Macaca nemestrina) [5]. In 1932, Knowles and Das Gupta reported the first experimental transmission of this simian malaria to human [6]. The first natural infection of $P$. knowlesi in human was reported later in 1965 in an American traveller who returned home from peninsular Malaysia [7].

Over the past decade, most countries in Southeast Asia and some in Asia have reported the presence of $P$. knowlesi, namely: Singapore [8], Thailand [9], Myanmar [10], Philippines [11], Indonesia [12, 13], Vietnam [14], Cambodia [15], Brunei [16], China [17]. Recently, Tyagi et al. reported human $P$. knowlesi infections from the Andaman and Nicobar Islands of India which are geographically nearby these Southeast Asian countries [18]. To date, 33 simian malarial parasites are documented in several prosimians, New World and Old World monkeys, African and Asian apes [19-22]. Plasmodium knowlesi, Plasmodium cynomolgi, Plasmodium inui, Plasmodium coatneyi, and Plasmodium fieldi are the five common species of simian malaria parasites in M. fascicularis and M. nemestrina [23].

Malaysia is considered endemic for malaria, mainly in the forested, mountainous and inaccessible areas of Malaysian Borneo comprising the states of Sabah and Sarawak, and peninsular Malaysia. A Malaria Eradication Programme was started in Sabah and Sarawak in 1961 and in peninsular Malaysia in 1967. Since then, there has been a significant reduction in the transmission of human malaria from $P$. falciparum and $P$. vivax whereas a significant increase in microscopy-diagnosed $P$. knowlesi/P. malariae cases was reported [24-26]. According to the Annual Report of the Ministry of Health Malaysia, $P$. knowlesi was the predominant (38\%) species followed by $P$. vivax (31\%) in 2012 [27]. Most of the cases were contributed by Sabah and Sarawak, while in peninsular Malaysia a high number of $P$. knowlesi malaria cases were reported from Pahang $[28,29]$. The most developed state of Malaysia is Selangor which is still vulnerable to malaria [30]. In the last 5 years, $P$. knowlesi/P. malariae infection in humans was shown to be highest in Hulu Selangor district, one of the nine districts in Selangor [31]. This could be due to several factors, such as heightened human infringement into forests, high rate of construction and development, and the presence of secondary rainforests in the locality of urban and suburban residences which offer suitable habitats for mosquitoes and monkeys that can harbour various species of simian malaria parasites [30].
In recent years, an experimental analysis was carried out by Vythilingam et al. [31] to elucidate the transmission of $P$. knowlesi malaria in Hulu Selangor district. The study mainly focused on the epidemiology of $P$. knowlesi by determining the human infection and vector distribution. However, the limitation of the study was that there was no information regarding infection in the macaques from that same study area. In view of this gap of knowledge, it is imperative to understand the infection rate of simian malaria in macaque hosts. Hence, the main objective of this study was to determine the prevalence of malaria parasites in macaques, namely $P$. knowlesi, $P$. cynomolgi, P. coatneyi, P. inui, and P. fieldi in Hulu Selangor. The findings from this study have strengthened the evidence that Hulu Selangor is a potential risk area for knowlesi malaria transmission due to the presence of infected macaques. Besides, other malaria parasites such as $P$. cynomolgi and $P$. inui which have potential to infect humans were also present.

\section{Methods}

\section{Collection of macaque blood samples}

In June 2014, a total of 70 macaque blood samples from Hulu Selangor (Fig. 1) were provided by the Department of Wildlife and National Parks Peninsular Malaysia, Kuala Lumpur, Malaysia. The macaques were caught by the Wildlife Department under a national surveillance programme, approved by the Department's Animal Welfare Committee.

\section{DNA extraction}

DNA was extracted from $200 \mu \mathrm{L}$ blood using PureLink ${ }^{\text {TM }}$ Genomic DNA Kit (Life Technologies, USA) according to manufacturer's protocol. Purified DNA was eluted from the column with $100 \mu \mathrm{L}$ elution buffer and stored at $-20{ }^{\circ} \mathrm{C}$ until further use.

\section{Conventional PCR for screening of blood samples for detection of Plasmodium genus}

Blood samples were screened for $18 \mathrm{~S}$ ribosomal RNA genes for detection of Plasmodium by using conventional PCR with the thermal condition and primers sequences as described [32]. The PCR was carried out in a total of $20 \mu \mathrm{L}$ volume containing $1 \times$ reaction buffer $(5 \times$ Green Go Tag Flexi Buffer (Promega Madison WI, USA), $2.5 \mathrm{mM} \mathrm{MgCl} 2$ (Promega), $0.2 \mathrm{mM}$ of each deoxynucleoside triphosphate (Promega), $0.3 \mu \mathrm{M}$ of each primers (PlasF5'-AGT GTG TAT CAA TCG AGT TTC T- ${ }^{\prime}$ and PlasR5'-CTT GTC ACT ACC TCT CTT CTT TAG A-3') [32], 0.2 U of Go Taq DNA polymerase (Promega) and $2 \mu \mathrm{L}$ genomic DNA template was used. Thermal conditions were as follows: an initial denaturation at $95^{\circ} \mathrm{C}$ for 4 min followed by 35 cycles of amplification at $95^{\circ} \mathrm{C}$ for $30 \mathrm{~s}$, annealing at $55{ }^{\circ} \mathrm{C}$ for $30 \mathrm{~s}$, extension at $72{ }^{\circ} \mathrm{C}$ for 


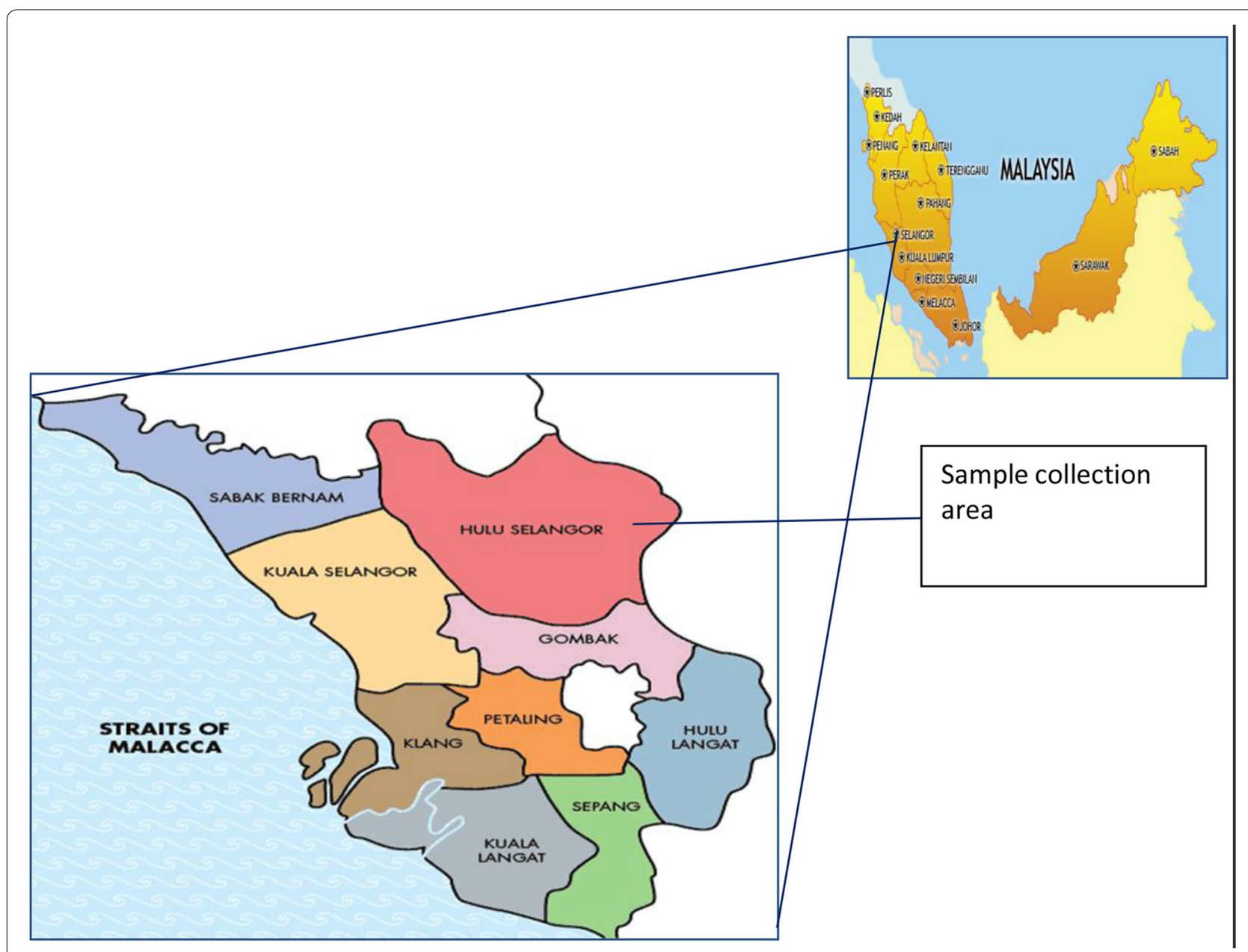

Fig. 1 Map of Selangor State. Indicator showing the sample collection place of the study

$30 \mathrm{~s}$ followed by a final extension at $72{ }^{\circ} \mathrm{C}$ for $2 \mathrm{~min}$. Positive and negative controls were included with all the PCR reactions (Mega Cycler ${ }^{\mathrm{TM}}$, Edvotex, The Biotechnology and Education Company Ltd, China). The PCR products were subjected to electrophoresis in $2 \%$ agarose gel and visualized under UV light.

\section{Nested PCR to detect Plasmodium species}

All Plasmodium positive samples were subjected to nested PCR to detect the different species using the primer sequences as reported previously [4, 33, 34]. The primers were based on $18 \mathrm{~S}$ ribosomal RNA and small sub-unit RNA genes. Nest 1 PCR mixtures were performed in a total of $20 \mu \mathrm{L}$ reaction mixture. The amplification mixture contained the following in final concentration of $1 \times$ Green Go Tag Flexi Buffer (Promega) $2.5 \mathrm{mM} \mathrm{MgCl}$ (Promega), $200 \mathrm{mM}$ each-dNTP (Promega), $0.25 \mu \mathrm{M}$ of each primers, rPLU1: (5'-TCA AAG ATT AAG CCA TGC AAG TGA-3' and rPLU5: (5'CCT GTT GTT GCC TTA AAC TCC-3') [34] and $1.25 \mathrm{U}$ of Go Taq DNA polymerase (Promega) and $2 \mu \mathrm{L}$ genomic DNA template was used for each reaction. The cycling parameters were as follows: an initial denaturation at $94{ }^{\circ} \mathrm{C}$ for $4 \mathrm{~min}$ followed by 35 cycles of denaturation at $94{ }^{\circ} \mathrm{C}$ for $30 \mathrm{~s}$; annealing at $55{ }^{\circ} \mathrm{C}$ for $60 \mathrm{~s}$, extension at $72{ }^{\circ} \mathrm{C}$ for $60 \mathrm{~s}$ followed by a final extension at $72{ }^{\circ} \mathrm{C}$ for $4 \mathrm{~min}$. Two $\mu \mathrm{L}$ of nest 1 product was used as template DNA for nest 2 PCR. The PCR conditions were exactly the same as nest 1 except the annealing temperature. The primer sequence for the species and annealing temperatures are shown in Table 1 . The PCR products were subjected to electrophoresis in $2 \%$ agarose gel and visualized under UV light.

\section{Sequencing of PCR-amplified DNA}

The PCR products were visualized over gel electrophoresis using $2 \%$ agarose gel and the amplified products from the gel was purified and sequenced on an ABI 3730xl sequencer (Genomics Bioscience and Technology Co Ltd, Taiwan) using the PCR primers. 
Table 1 Sequences of primers adopted from Singh et al. [4] and Lee et al. [34] with respective annealing temperatures and product size

\begin{tabular}{|c|c|c|c|c|}
\hline Species & Name of primer & Sequences $\left(5^{\prime}-3^{\prime}\right)$ & Annealing temperature $\left({ }^{\circ} \mathrm{C}\right)$ & Product size \\
\hline \multirow[t]{2}{*}{ P. knowlesi } & Pmk8 & GTTAGCGAGAGCCACAAAAAAGCGAAT & 60 & 153 \\
\hline & Pmk9r & ACTCAAAGTAACAAAATCTTCCGT & & \\
\hline \multirow[t]{2}{*}{ P.cynomolgi } & $\mathrm{CY} 2 \mathrm{~F}$ & GATTTGCTAAATTGCGGTCG & 61 & 137 \\
\hline & CY4R & CGGTATGATAAGCCAGGGAAGT & & \\
\hline \multirow[t]{2}{*}{ P. coatneyi } & PctF1 & CGCTTTTAGCTTAAATCCACATAACAGAC & 61 & 504 \\
\hline & PctR1 & GAGTCCTAACCCCGAAGGGAAAGG & & \\
\hline \multirow[t]{2}{*}{ P. inui } & PinF2 & CGTATCGACTTTGTGGCATTTTTCTAC & 61 & 479 \\
\hline & INAR3 & GCAATCTAAGAGTTTTAACTCCTC & & \\
\hline \multirow[t]{2}{*}{ P. fieldi } & PfldF1 & GGTCTTTTTTTTGCTTCGGTAATTA & 62 & 421 \\
\hline & PfldR2 & AGGCACTGAAGGAAGCAATCTAAGAGTTTC & & \\
\hline
\end{tabular}

\section{Data analysis}

The sequence data were analysed using the BLAST program [35] and the sequences aligned using the Clustal W programs in Bioedit package [36]. The phylogenetic trees were constructed by the neighbour-joining (NJ) and maximum likelihood (ML) methods with maximum composite likelihood model and Tamura 3-parameter model, respectively, with 1000 bootstrap replicates in MEGA 6.0 software [37-39].

\section{Results}

In this study, a total of 70 long-tailed macaques (M. fascicularis) blood samples were screened using conventional PCR to detect malaria parasites, among which 35 (50 \%) samples were Plasmodium positive. From the positive samples, five species of Plasmodium parasites (Fig. 2) were detected. The infection rates in long-tailed macaques for P. knowlesi, P. cynomolgi, P. coatneyi, $P$. inui and P. fieldi were found to be 60, 51.4, 45.7, 65.7 and $2.9 \%$ respectively (Table 2). Multiple infections with Plasmodium species were observed in these samples. The frequency of single, dual, triple, and quadruple infections of long-tailed macaques was 25.7, 31.4, 34.3, and $8.6 \%$, respectively (Table 3 ). The prevalence of mixed infection was higher $(74.3 \%)$ compared to mono-infection (25.7\%). Only nine macaques had mono-infection with P. knowlesi (four), P. cynomolgi (two) P. coatneyi (two) and $P$. fieldi (one). None of the macaques had mono-infection with $P$. inui. A total of 11 macaques $(31.4 \%)$ had dual infection, amongst them the prevalence of infection with $P$. knowlesi and P. inui was highest (36.4\%) followed by $P$. knowlesi and P. cynomolgi (9.1\%), P. cynomolgi and P. inui (27.3\%), P. coatneyi and P. inui (18.2\%), P. cynomolgi and P. coatneyi (9.1\%) (Table 3$)$.

Among the total Plasmodium-positive cases, most of the macaques had triple infection $(34.3 \%)$ with $P$. knowlesi, P. coatneyi and P. inui (33.3\%), P. knowlesi, P. cynomolgi and P. inui (33.3\%), P. cynomolgi, P. coatneyi and P. inui (25\%), P. knowlesi P. cynomolgi and P. coatneyi $(8.3 \%)$ (Table 3$)$. Whilst only three macaques were infected with all four species of Plasmodium parasites.

\section{Sequencing data analysis}

The identified species-specific fragment of 18SSU rRNA of Plasmodium species was sequenced to confirm the species. The nucleotide sequence of 18SSU rRNA fragment of simian malaria parasites identified in this study was compared with the sequences obtained from GenBank. The phylogenetic reconstruction of the five simian malaria parasites using the NJ method showed (Fig. 3) that malaria parasites isolated from Hulu Selangor were clustered in five separate clades with the reference genes from GenBank. The topology originates using the $\mathrm{ML}$ method was similar to the NJ tree, which strongly supports the results obtained by NJ. Sequences reported in this study (18S rRNA A-type) have been submitted to GenBank, under accession numbers: KT124141KT124216. The other sequences (also A-type) used as references obtained from GenBank are as follows: JX870044, KC581782, FJ619099, FJ619083, JF681166 and JQ627158.

\section{Discussion}

The screening of macaques in Hulu Selangor illustrated that $\sim 50 \%$ of the macaques were positive and five common species of simian Plasmodium: $P$. knowlesi, P. cynomolgi, P. coatneyi, P. inui and P. fieldi were present. Plasmodium inui had the highest prevalence $(65.7 \%)$ followed by $P$. knowlesi $(60 \%)$. The high infection rate indicates a high intensity of transmission occurring among long-tailed macaques in Hulu Selangor. This is similar to a study conducted in 


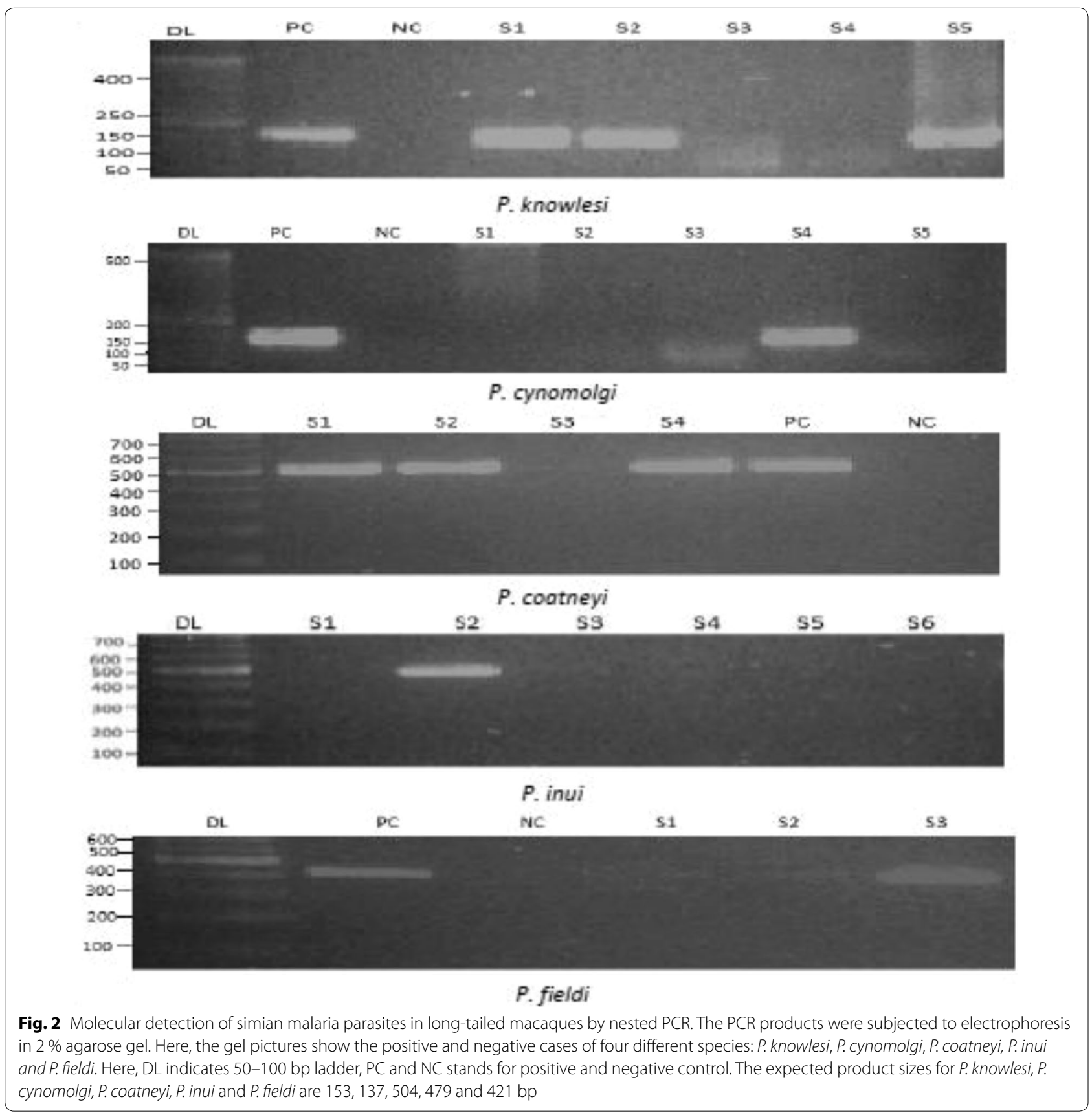

Kapit, Sarawak where the prevalence of $P$. inui infection in long-tailed macaques (82 \%) was predominant compared to other species [34]. In Sabah, Malaysian Borneo it was also found that $P$. inui was the most common parasite in both $M$. fascicularis and $M$. nemestrina [40]. However, in Singapore P. knowlesi was the predominant species (68.2 \%) among longtailed macaques [32]. In Kuala Lipis, Pahang, where macaques were screened only for P. knowlesi, $13.7 \%$ were positive [29]. However, there was no P. knowlesi infection detected in Selangor from 41 macaques captured in urban areas and two macaques from Kuala Lumpur [29], which may be due to the absence of competent vectors for simian malaria transmission in urban areas surveyed [32]. It must be noted though, that the work did not report on other species of Plasmodium. In addition, Ho et al. reported that $64.5 \%$ of 107 blood samples from long-tailed macaques were Plasmodium positive and among these $23.3 \%$ were positive for P. knowlesi in Selangor [41]. 
Table 2 Malaria infection in long tailed macaques

\begin{tabular}{llllll}
\hline Species & $\begin{array}{l}\text { Infected } \\
\text { (N) }\end{array}$ & $\begin{array}{l}\text { Percent- } \\
\text { age }\end{array}$ & $\begin{array}{l}\text { Non } \\
\text { infected } \\
\text { (N) }\end{array}$ & $\begin{array}{l}\text { Percent- } \\
\text { age }\end{array}$ & Total \\
\hline P. knowlesi & 21 & 60 & 14 & 40 & 35 \\
P. cynomolgi & 18 & 51.4 & 17 & 48.6 & 36 \\
P. coatneyi & 16 & 45.7 & 19 & 54.3 & 35 \\
P. inui & 23 & 65.7 & 12 & 34.3 & 35 \\
P. fieldi & 1 & 2.9 & 34 & 97.1 & 35 \\
\hline
\end{tabular}

Table 3 Mixed species: infection in long tailed macaques

\begin{tabular}{|c|c|c|c|c|}
\hline Infection type & Species & Infected & Total & Percentage \\
\hline \multirow[t]{4}{*}{ Single } & Pk & 4 & 9 & 25.7 \\
\hline & Pcy & 2 & & \\
\hline & Pct & 2 & & \\
\hline & Pfi & 1 & & \\
\hline \multirow[t]{5}{*}{ Dual } & $\mathrm{Pk}+\mathrm{Pin}$ & 4 & 11 & 31.4 \\
\hline & $P k+P c y$ & 1 & & \\
\hline & Pcy + Pin & 3 & & \\
\hline & Pct + Pin & 2 & & \\
\hline & $P c y+P c t$ & 1 & & \\
\hline \multirow[t]{4}{*}{ Triple } & $P k+P c t+P i n$ & 4 & 12 & 34.3 \\
\hline & $P k+P c y+P i n$ & 4 & & \\
\hline & $P c y+P c t+P i n$ & 3 & & \\
\hline & $\mathrm{Pk}+\mathrm{Pcy}+\mathrm{pct}$ & 1 & & \\
\hline Quadruple & $P k+P c y+P c t+P i n$ & 3 & 3 & 8.6 \\
\hline Total & & 35 & 35 & 100 \\
\hline
\end{tabular}

Pk P. knowlesi, Pcy P. cynomolgi, Pct P. coatneyi, Pin P. inui, Pfi P. fieldi

In a study from Thailand, in 2008 they did not find any $P$. knowlesi in the macaques; only P. inui and P. coatneyi were found [42]. In a subsequent study, the infection rate of P. inui (38.9\%) was highest compared to P. coatneyi (16.7 \%) followed by P. knowlesi at $5.6 \%$ [43]. The high infection rate for $P$. inui is similar to the findings from the current study $(65.7 \%)$, although at a lower rate. JonesEngel et al. reported one monkey (3.2 \%) was infected by $P$. knowlesi among 31 in Indonesia [44]. It also needs to be noted that the study focused only on P. knowlsei. The results are summarized in Table 4.

Simian malaria parasites are of great interest in Hulu Selangor as $P$. knowlesi infections are on the increase in Selangor. The recent emergence of $P$. knowlesi infections in humans may be due to close proximity of competent vectors, together with monkeys and humans, leading to conditions favourable for inter-species transmission to occur. This has occurred with deforestation and human encroachment on the natural habitats of the monkeys increasing the chance of human infection by simian malaria [31]. Recently, Anopheles introlatus has been incriminated as a vector for P. knowlesi in Hulu Selangor [31]. The presence of this vector coupled with positive macaques shows that simian malaria can pose a serious public health problem to humans in the near future. It has also been reported that human P. knowlesi is an admixture of two divergent parasite populations associated with the two different macaque hosts dwelling in the forest [45] and studies have confirmed that there were two types of $P$. knowlesi parasites in patients from Sarawak [46]. In Sabah, it has been shown that there were differences in the sequences of $P$. knowlesi from longtailed and pig-tailed macaques [40].

The zoonotic potential of $P$. cynomolgi parasite had been discovered after an accidental infection in humans by mosquito bites in the laboratory [47]. The prevalence of $P$. cynomolgi in long-tailed macaques was $51.4 \%$. In addition, this species has attracted a lot of attention recently as one case of natural infection in humans has been reported from Hulu Terengganu, Malaysia [48]. Besides, it has also been demonstrated that $P$. inui was infectious to humans in laboratory studies [49] and this was the predominant species $(65.7 \%)$ in this study. However, there has been no report of this parasite in humans and this may be due to misdiagnosis by microscopy since the parasites have overlapping morphological characteristics with human malaria parasites.

The findings of this study has demonstrated the prevalence of five simian malaria parasites in their natural host, further highlighting the need to deliberate new strategies to prevent the potential zoonosis of the other simian malarias. Efforts are ongoing to study the genetic diversity of these malaria parasites as recent studies have indicated their importance $[45,46]$. Another prospective study would be the use of monkey-baited traps to capture and incriminate other mosquito species in their capacity to transmit simian malaria. The movement of these macaques also needs to be monitored in order to prevent their close proximity to humans.

\section{Conclusion}

This study showed the prevalence of simian malarias in the local monkey population of Hulu Selangor. It found that four simian Plasmodium species were present in long-tailed macaques and occurred commonly as multiple infections. The study has provided evidence that $P$. inui was the most prevalent $(65.7 \%)$ malaria parasite followed by $P$. knowlesi in long-tailed macaques in Selangor. The significance of zoonotic simian malaria parasites cannot be overlooked in the assessment of accumulative interfaces between humans and wild animals in the development of urbanization. Potentially more samples should be collected in order to obtain a better understanding on 


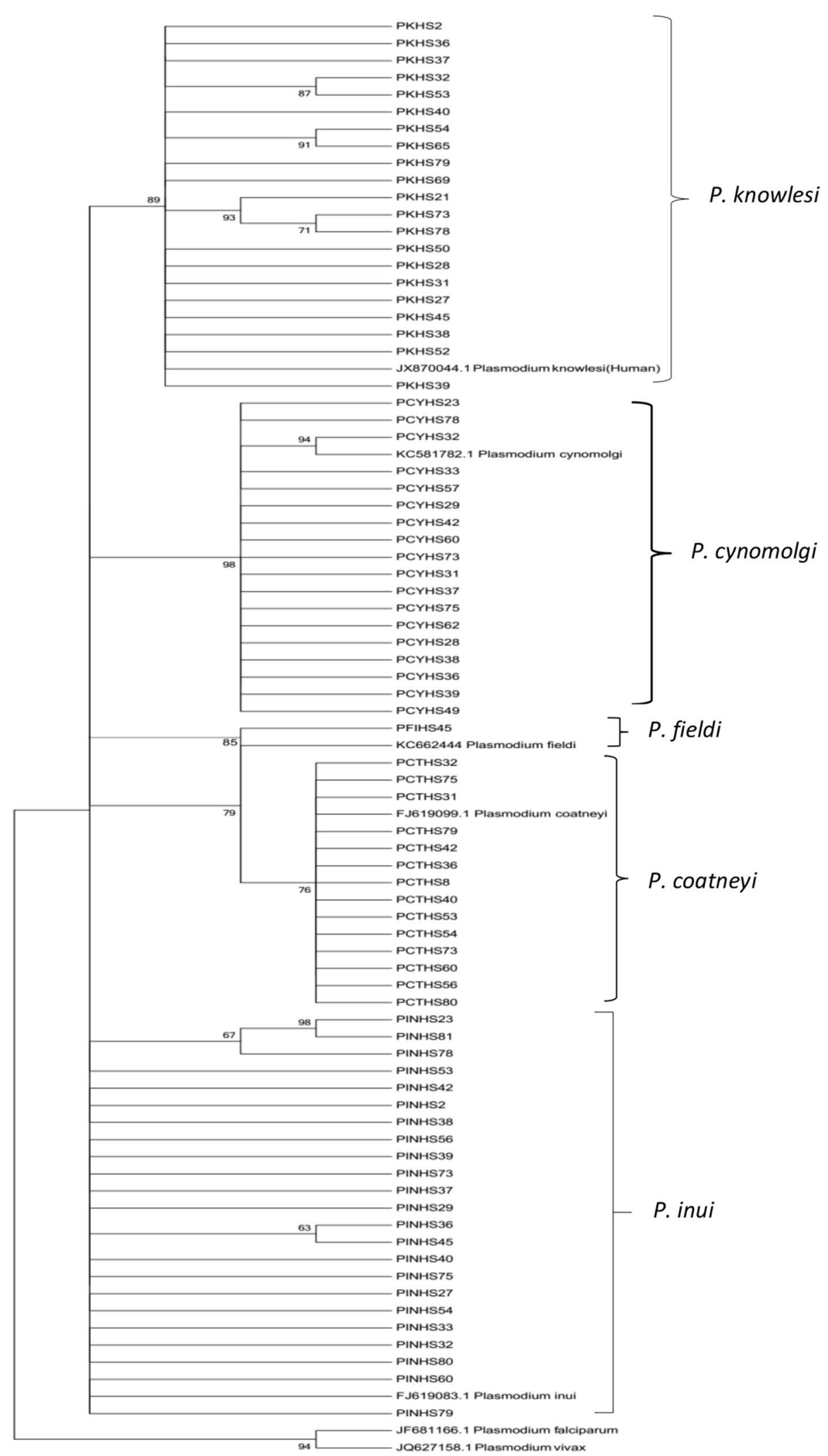

Fig. 3 Phylogenetic tree of simian malaria parasites on the basis of $18 \mathrm{~S}$ ribosomal RNA genes (A type) generated by neighbour-joining ( $\mathrm{NJ}$ ) method. NJ and ML methods yielded identical topologies and thus only the NJ tree is shown. The bootstraps percentage based on 1000 replicates are shown on the branches (bootstraps more than $60 \%$ shown in branches) 
Table 4 Summary of malaria infection in long tailed macaques in different countries

\begin{tabular}{|c|c|c|c|c|c|c|}
\hline Study area & Pk & Pcy & Pin & Pct & Pfi & Year \\
\hline Hulu Selangor (present study) & $60 \%$ & $51.4 \%$ & $65.7 \%$ & $45.7 \%$ & $2.9 \%$ & 2015 \\
\hline Kapit, Sarawak Malaysian Borneo ${ }^{a}$ & $78 \%$ & $56 \%$ & $82 \%$ & $66 \%$ & $4 \%$ & 2011 \\
\hline Singapore $^{b}$ & $68.2 \%$ & $66.6 \%$ & $1.5 \%$ & $3 \%$ & $16.7 \%$ & 2011 \\
\hline Kuala Lipis Pahang Malaysiac & $13.7 \%$ & - & - & - & - & 2008 \\
\hline Kuala Lumpur and Selangor State Malaysia ${ }^{c}$ & $0 \%$ & - & - & - & - & 2008 \\
\hline Selangor State, Malaysia ${ }^{d}$ & $23.3 \%$ & - & - & - & - & 2010 \\
\hline Ulu Bernam, Kuala Kubu Bharu, Malaysia & $0 \%$ & + & + & + & + & 2013 \\
\hline Thailand $^{f}$ & $0 \%$ & - & + & + & - & 2008 \\
\hline Thailand $^{g}$ & $5.6 \%$ & - & $38.9 \%$ & $16.7 \%$ & - & 2010 \\
\hline Indonesia ${ }^{h}$ & $3.2 \%$ & - & - & - & - & 2007 \\
\hline Sabah, Malaysian Borneo ${ }^{i}$ & + & + & + & + & + & 2014 \\
\hline
\end{tabular}

Pk P. knowlesi, Pcy P. cynomolgi, Pin P. inui, Pct P. coatneyi, Pfi P. fieldi, (+) positive

${ }^{\text {a }}$ Lee et al. [34]

b Irene [32]

c Vythilingam et al. [29]

d Ho et al. [41]

e Vythilingam et al. [31]

f Seethamchai et al. [42]

9 Putaporntip et al. [43]

h Jones-Engel et al. [44],

i Muehlenbein et al. [40]

the prevalence of simian malarias in monkeys all over Malaysia. These findings would be important for the planning and control of malaria strategies in the future. The genetic diversity of these parasites should also be studied.

\section{Authors' contributions}

RA, RQ, LTK, IV, and YALL conceived the idea and participated in the study design. RA, LTK, FTS, and BV were responsible for sample collection. RA, IV and LTK carried out the experiments and analysed the data. RA, RQ, KLT, IV. YALL and SDS drafted the manuscript. All authors read and approved the final manuscript.

\section{Author details}

'Department of Medicine, Faculty of Medicine, University of Malaya, 50603 Kuala Lumpur, Malaysia. ${ }^{2}$ Department of Parasitology, Faculty of Medicine, University of Malaya, 50603 Kuala Lumpur, Malaysia. ${ }^{3}$ Department of Wildlife and National Park (PERHILITAN), KM10, Jalan Cheras, 56100 Kuala Lumpur, Malaysia. ${ }^{4}$ State Vector Borne Disease Control Unit, Selangor State Health Department, Selangor, Malaysia. ${ }^{5}$ Department of Microbiology, Faculty of Medicine, University of Malaya, 50603 Kuala Lumpur, Malaysia.

\section{Acknowledgements}

The authors thank the University of Malaya for the opportunity to carry out this work. We are also thankful to the Department of Wildlife and National Parks, Peninsular Malaysia for sample collection from Selangor. The research work was funded by University of Malaya Exploratory Research Grant Scheme ER015-2013A; University of Malaya High Impact Research Grant UM.C/625/1/ HIR/099 J-00000-2011-73822

\section{Compliance with ethical guidelines}

\section{Competing interests}

The authors declare that they have no competing interests.
Received: 19 June 2015 Accepted: 22 August 2015

Published online: 05 October 2015

\section{References}

1. Cox-Singh J. Zoonotic malaria: Plasmodium knowlesi, an emerging pathogen. Curr Opin Infect Dis. 2012;25:530-6.

2. Farouk SE, Dolo A, Bereczky S, Kouriba B, Maiga B, Färnert A, et al. Different antibody-and cytokine-mediated responses to Plasmodium falciparum parasite in two sympatric ethnic tribes living in Mali. Microbes Infect. 2005;7:110-7.

3. WHO. World Malaria Report 2013. Geneva: World Health Organization; 2014 http://www.who.int/malaria/world_malaria_report_2014/en/. Accessed 1 Jun 2015

4. Singh B, Sung LK, Matusop A, Radhakrishnan A, Shamsul SS, Cox-Singh J, et al. A large focus of naturally acquired Plasmodium knowlesi infections in human beings. Lancet. 2004;363:1017-24.

5. White N. Plasmodium knowlesi: the fifth human malaria parasite. Clin Infect Dis. 2008:46:172.

6. Knowles R, Das Gupta B. A study of monkey-malaria and its experimental transmission to man. Ind Med Gaz. 1932;67:301-20.

7. Chin W, Contacos PG, Coatney GR, Kimball HR. A naturally acquired quotidian-type malaria in man transferable to monkeys. Science. 1965;149:865.

8. Ng OT, Ooi EE, Lee CC, Lee PJ, Ng LC, Pei SW, et al. Naturally acquired human Plasmodium knowlesi infection, Singapore. Emerg Infect Dis. 2008;14:814.

9. Jongwutiwes S, Putaporntip C, Iwasaki T, Sata T, Kanbara H. Naturally acquired Plasmodium knowlesi malaria in human, Thailand. Emerg Infect Dis. 2004;10:2211-3.

10. Jiang N, Chang Q, Sun X, Lu H, Yin J, Zhang Z, et al. Co-infections with Plasmodium knowlesi and other malaria parasites, Myanmar. Emerg Infect Dis. 2010;16:1476-8. 
11. Luchavez J, Espino F, Curameng P, Espina R, Bell D, Chiodini P, et al. Human infections with Plasmodium knowlesi, the Philippines. Emerg Infect Dis. 2008;14:811-3.

12. Figtree $M$, Lee $R$, Bain L, Kennedy T, Mackertich S, Urban M, et al. Plasmodium knowlesi in Human, Indonesian Borneo. Emerg Infect Dis. 2010;14:672-4.

13. Sulistyaningsih E, Fitri LE, Löscher T, Berens-Riha N. Diagnostic difficulties with Plasmodium knowlesi infection in humans. Emerg Infect Dis. 2010;16:1033

14. Eede P, Van H, Van Overmeir C, Vythilingam I, Duc T, Hung L, et al. Human Plasmodium knowlesi infections in young children in central Vietnam. Malar J. 2009;8:249.

15. Khim N, Siv S, Kim S, Mueller T, Fleischmann E, Singh B, et al. Plasmodium knowlesi infection in humans, Cambodia, 2007-2010. Emerg Infect Dis. 2011;17:1900

16. Ninan T, Nalees K, Newin M, Sultan Q, Than MM, Shinde S, et al. Plasmodium knowlesi malaria infection in human. Brunei Int Med J. 2012:8:358-61.

17. Zhu H, Li J, Zheng H. Human natural infection of Plasmodium knowlesi. Chin J Parasitol Parasit Dis. 2006;24:70.

18. Tyagi RK, Das MK, Singh SS, Sharma YD. Discordance in drug resistanceassociated mutation patterns in marker genes of Plasmodium falciparum and Plasmodium knowlesi during coinfections. J Antimicrob Chemother. 2013;68:1081-8.

19. Coatney RG, Collins WE, Warren M, Contacos PG. The Primate Malarias. Washington: U.S. Government Printing Office; 1971.

20. Leclerc M, Hugot J, Durand P, Renaud F. Evolutionary relationships between 15 Plasmodium species from New and Old World primates (including humans): a 18S rDNA cladistic analysis. Parasitol. 2004;129:677-84.

21. Ollomo B, Durand P, Prugnolle F, Douzery E, Arnathau C, Nkoghe D, et al. A new malaria agent in African hominids. PLoS Pathog. 2009;5:e1000446.

22. Krief S, Escalante AA, Pacheco MA, Mugisha L, André C, Halbwax M, et al. On the diversity of malaria parasites in African apes and the origin of Plasmodium falciparum from Bonobos. PLoS Pathog. 2010;6:e1000765.

23. Eyles DE. The species of simian malaria: taxonomy, morphology, life cycle, and geographical distribution of the monkey species. J Parasitol. 1963:49:866-87.

24. Rahman KM. Epidemiology of malaria in Malaysia. Rev Infect Dis. 1982:4:985-91.

25. Lim E. Current status of malaria in Malaysia. Southeast Asian J Trop Med Pub Health. 1992:23:43-9.

26. William T, Rahman HA, Jelip J, Ibrahim MY, Menon J, Grigg MJ, et al. Increasing incidence of Plasmodium knowlesi malaria following control of P. falciparum and P. vivax malaria in Sabah, Malaysia. PLoS Neg Trop Dis. 2013;7:e2026.

27. Annual Report Ministry of Health (2012) http://www.moh.gov.my/ images/gallery/publications/md/ar/2012 en.pdf. Assessed 1 Jun 2015.

28. Yusof R, Lau YL, Mahmud R, Fong MY, Jelip J, Ngian HU, et al. High proportion of knowlesi malaria in recent malaria cases in Malaysia. Malar J. 2014;13:168.

29. Vythilingam I, NoorAzian YM, Huat TC, Jiram Al, Yusri YM, Azahari AH, et al. Plasmodium knowlesi in humans, macaques and mosquitoes in peninsular Malaysia. Parasit Vectors. 2008;1:26.

30. Braima KA, Sum JS, Ghazali ARM, Muslimin M, Jeffery J, Lee WC, et al. Is there a risk of suburban transmission of malaria in Selangor, Malaysia? PLoS One. 2013:8:e77924.

31. Vythilingam I, Lim YA, Venugopalan B, Ngui R, Leong CS, Wong ML, et al. Plasmodium knowlesi malaria an emerging public health problem in Hulu Selangor, Selangor, Malaysia (2009-2013): epidemiologic and entomologic analysis. Parasit Vectors. 2014;7:436.

32. Irene LM. Identification and molecular characterisation of simian malaria parasites in wild monkeys of Singapore. National University of Singapore MSc Thesis. 2011.

33. Singh B, Bobogare A, Cox-Singh J, Snounou G, Abdullah MS, Rahman $H$. A genus and species specific nested polymerase chain reaction malaria detection assay for epidemiologic studies. Am J Trop Med Hyg 1999;60:687-92
34. Lee KS, Divis PCS, Zakaria SK, Matusop A, Julin RA, Conway DJ, et al. Plasmodium knowlesi: reservoir hosts and tracking the emergence in humans and macaques. PLoS Pathog. 2011;7:e1002015.

35. Madden T. The BLAST sequence analysis tool. In: Bethesda (MD): National Center for Biotechnology Information (US). 2nd ed. NCBI: The NCBI Handbook (Internet); 2013.

36. Hall T. BioEdit: an important software for molecular biology. GERF Bull Biosci. 2011;2:60-1.

37. Saitou N, Nei M. The neighbour-joining method: a new method for constructing phylogenetic tree. Mol Biol Evol. 1987;4:406-25.

38. Tamura K, Peterson D, Peterson N, Stecher G, Nei M, Kumar S. MEGA5: molecular evolutionary genetics analysis using maximum likelihood, evolutionary distance, and maximum parsimony methods. Mol Biol Evol. 2011;28:2731-9.

39. Tamura K. Estimation of the number of nucleotide substitutions when there are strong transition-transversion and $\mathrm{G}+\mathrm{C}$-content biases. Mol Biol Evol. 1992;9:678-87.

40. Muehlenbein MP, Pacheco MA, Taylor JE, Prall SP, Ambu L, Nathan S, et al Accelerated diversification of nonhuman primate malarias in southeast Asia: adaptive radiation or geographic speciation? Mol Biol Evol. 2015;32:422-39.

41. Ho G, Lee C, Abie M, Zainuddin Z, Japnin J, Topani R, et al. Prevalance of Plasmodium in the Long-tailed Macaque (Macaca fasicularis) from Selangor, Malaysia. In: Proc 13th Assoc Inst Trop Vet Med Conf; 2010. p. 49.

42. Seethamchai S, Putaporntip C, Malaivijitnond S, Cui L, Jongwutiwes S. Malaria and Hepatocystis species in wild macaques, southern Thailand. Am J Trop Med Hyg. 2008;78:646-53.

43. Putaporntip C, Jongwutiwes S, Thongaree S, Seethamchai S, Grynberg P, Hughes AL. Ecology of malaria parasites infecting Southeast Asian macaques: evidence from cytochrome b sequences. Mol Ecol. 2010;19:3466-76.

44. Jones-Engel L, Engel G, Schillaci M, Pacheco M, Escalante A. Malarial monkeys: reservoir for zoonotic infection? Am J Primatol. 2007:69:40-1.

45. Divis PC, Singh B, Anderios F, Hisam S, Matusop A, Kocken CH, et al. Admixture in humans of two divergent Plasmodium knowlesi populations associated with different macaque host species. PLoS Pathog. 2015;11:e1004888.

46. Pinheiro MM, Ahmed MA, Millar SB, Sanderson T, Otto TD, Lu WC, Krishna S, Rayner JC, Cox-Singh J. Plasmodium knowlesi genome sequences from clinical isolates reveal extensive genomic dimorphism. PLoS One. 2015;10:e0121303.

47. Eyles DE, Coatney GR, Getz ME. Vivax-type malaria parasite of macaques transmissible to man. Science. 1960;131:1812-3.

48. Ta TH, Hisam S, Lanza M, Jiram Al, Ismail N, Rubio JM. First case of a naturally acquired human infection with Plasmodium cynomolgi. Malar J. 2014;13:68.

49. Coatney GR, Chin W, Contacos PG, King HK. Plasmodium inui, a quartantype malaria parasite of Old World monkeys transmissible to man. J Parasitol. 1966:52:660-3.

\section{Submit your next manuscript to BioMed Central and take full advantage of:}

- Convenient online submission

- Thorough peer review

- No space constraints or color figure charges

- Immediate publication on acceptance

- Inclusion in PubMed, CAS, Scopus and Google Scholar

- Research which is freely available for redistribution

Submit your manuscript at

www.biomedcentral.com/submit 